\title{
microRNA-128 mediates CB1 expression and regulates NF-KB/p-JNK axis to influence the occurrence of diabetic bladder disease
}

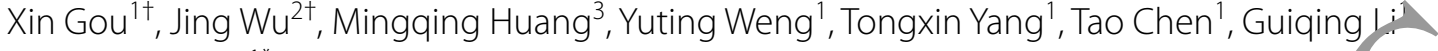 \\ and Kewei Fang ${ }^{1 *}$
}

\begin{abstract}
Background: Diabetic bladder disease is common complications of diabetes, its sympt $\varsigma$ are diverse, can be due to different stages. In this study we investigate the mechanism of miR-128 target, y CB1 expression to mediate the occurrence of diabetic bladder disease.
\end{abstract}

Methods: Bioinformatics analysis predicts related regulatory factors of miR-12 $\delta$ diabetic bladder disease. Models of diabetic bladder lesions were constructed in male SD rats by intraperitc iniection of streptozotocin at $65 \mathrm{mg} / \mathrm{kg}$ body weight. The expression of miR-128 and CB1 mRNA in bladder tissus of 5 ach group was detected by RT-qPCR, and CB1, NF-KB, p-JNK and BCl2 protein expression was detected by West ren Blotting. We tested the function of the bladder by urodynamics, detected the pathological charar erist of the bladder tissue by HE staining, and verified the targeting relationship between miR-128 and CB1 thron the ediction of the biological website, dual luciferase reporter gene assay and RIP.

Results: miR-128 was highly expressed in the blaa asut of diabetic rats. Inhibition of miR-128 could improve the occurrence of diabetic bladder lesions in rats niR-128,, $1 /$ target the inhibition of CB1 expression, and high expression of CB1 could antagonize miR-128 aga ist betic bladder. In the diabetic bladder, miR-128 can regulate the expression of NF-KB and p-JNK through D $\mathrm{B}$ t and net the level of apoptosis. miR-128 regulates NF-KB/p-JNK through CB1, thus affecting the occurrence of diabetic bladder disease.

Conclusion: The high expression of iR-128 tan down-regulate the expression of CB1, promote the activation of NF-KB and $p-J N K$, increase the level of a prosis and promote the occurrence of diabetic bladder disease.

Keywords: microRNA-128, CB, B...S, Bladder disease, NF-KB, P-JNK, Apoptosis

\section{Background}

Diabetic bladd disease / common complications of diabetes, its $s_{x} \mathrm{mp}$ ns are diverse, can be due to different stages, Dut main y manifested by impaired feeling

\section{orres sndence. 2482099228@qq.com}

ing Wu are co-first authors

1 De, ment of Urology, The Second Affiliated Hospital of Kunming

Medica Jniversity, No. 374, Dianmian Dadao, Kunming, Yunnan 650101, People's Republic of China

Full list of author information is available at the end of the article of bladder filling and weakened contractility changes in urination characteristics, and may be complicated by urinary tract infection and bladder urination Tube reflux, hydronephrosis, kidney stones, and eventually uremia [1]. The number of people with diabetes has continued to increase in recent years [2]. Diabetic cystitis (DCP) is a systemic disease associated with diabetes in the urinary system of humans and animals, accounting for more than $80 \%$ of people with diabetes [3]. The pathogenesis of DCP is still unclear, it is a complex and has many incentives, and the course of the disease is closely related to time. 
Myogenic, currently considered neurogenic and urethral epithelial changes are the main causes of DCP [4, 5]. Many studies have tried to elucidate the mechanism of DCP, but it is still unclear. Therefore, the treatment of DCP is greatly restricted [6].

miRNAs are a group of highly conserved small RNA molecules that can regulate gene expression functions More and more studies show that miRNAs play an important role in many physiological processes $[7,8]$. Mutations or disorders of miRNAs are related to a variety of human tumors. Over control protein coding to play a role in promoting or suppressing cancer [9]. Studies have shown that miR-128 expression in tumors of the nervous system, breast and prostate cancer, tumor expression is down-regulated [10], and through its target genes such as the oncogene Bmi-1 [11], EGFR [12], p70S6K1 [13], E2F3 [14], miR-128 play a role in suppressing cancer. However, level of miR-128a and its downstream regulated signals in diabetes have not been reported.

Recent years more reports were focused on the role of miR-144, also like miR-128 carcinogenesis because it is dysregulated and involved in the tumorigenesis of various cancer, such as lung cancer [15], osteosarcoma [16], hepatocellular carcinoma [17], thyroid cancer [18], bladder cancer [19] and colorectal carcinoma [20]. However, the biological functions and underlying molesalar mechanism of miR-144 in DCP are not yet des be' Therefore, we investigate the biological role and po. tial mechanism of miR-144 in DCP by se 1 exper, ments in vitro and tumor growth of xenorraft in $\mathrm{o}$ and in vitro.

\section{Methods}

\section{Bioinformatics analysis}

Through bioinformatics welsive microT (http:// diana.imis.athena-in tion/gr/DianaTools/index .php? $r=$ microT_CDS T mootScan (http://www.targe tscan.org/vert_72/, mı "alk (http://mirwalk.umm.uniheidelberg.de// nd $\mathrm{RN}_{2}$ inter (http://www.rna-socie ty.org/rnainter/), L. downstream target genes of miR128 in rats were joil dy predicted using different binding site 9 hin algorithms. We used the jvenn tool (ht'/jven or/ouse.inra.fr/app/example.html) to take e ir ersection of four predicted results for target gene so ming. The interaction between genes was analyzed thro $Y$ the STRING website (https://string-db.org/), and the results of the interaction analysis were visualized using Cytoscape 3.5.1. In order to further predict the downstream regulatory factors of genes, we set the keyword "diabetic bladder disease" through the GeneCards database (https://www.genecards.org/) to find related genes, and used the STRING website to analyze the gene interactions. The relationship predicted downstream regulatory genes. The co-expression relationship of downstream genes was obtained through Chipbase v2.0 website (http://rna.sysu.edu.cn/chipbase/).

\section{Establishment of Diabetic Mellitus (DM) rat model}

A total of 100 SPF male SD rats (purchased fron the Experimental Animal Center of China Medica' University), weighing 180-250 g, were randomly divid nto 3 groups after fasting for $12 \mathrm{~h}$ : normal control grou $\mathrm{P} / \mathrm{C}$ group, $\mathrm{n}=16$ ); Polyuria control group $(\mathrm{r}$ roup, $1=16$ ), hypertonic polyuria induced with $5 / 0$ suc drinking water; diabetes group ( $\mathrm{M}$ group, $\mathrm{r}=68$ ), single intraperitoneal injection of trepto-otocin (STZ; dissolved at $\mathrm{pH}=4.2$ in 0.1 ol/ $\mathrm{L}$.nic acid buffer; Sigma, St. Louis, MO) at $65 \mathrm{~h} / \mathrm{kg}$ body weight. The rats in the $\mathrm{NC}$ group a the $\mathrm{PU}$ group were intraperitoneally injected with the s. e dose of normal saline. At 4 weeks after ST $\angle$ L ection, the blood glucose level was confirmed to $b_{b}$ br $\quad \mathrm{mg} / \mathrm{dl}$, and the rats with urine glucose test strip ++ were diabetic rats. All rats were free to ea drink. At 6 and 12 weeks, 8 rats were randomly selected, $\mathrm{om}$ each group, placed in a metabolic cage, and urine of rats was collected and weighed for 24 nd then performed with urodynamic experiments. This xperimental procedure and animal use protocol 1 e been approved by the Animal Ethics Committee of the Second Affiliated Hospital of Kunming Medical University.

\section{Grouping and processing of experimental animals}

The rats in the NC group, the PU group, and the successfully modeled DM group were anaesthetized with $200 \mathrm{~g} / \mathrm{L}$ urethane (injection dose $1.5 \mathrm{~g} / \mathrm{kg}$ ) after $6 \mathrm{~h}$ of fasting. Ureter is inserted through the urethra to empty the urine after anesthesia. The rats in the NC group and the PU group were perfused with $0.2 \mathrm{ml}$ of PBS solution through the ureter. There were 56 of DM group successfully modeled rats, and the modeling success rate was 93.33\%. The modeled rats were divided into the following groups, 8 in each group: mimic NC group (urinary catheter perfusion with $0.2 \mathrm{~mL}$ mimic NC), miR-128 mimic group (urinary catheter perfusion with $0.2 \mathrm{~mL}$ miR-128 mimic), inhibitor NC group (urinary catheter perfusion with $0.2 \mathrm{~mL}$ inhibitor NC), miR-128 inhibitor group (urinary catheter perfusion with $0.2 \mathrm{~mL}$ miR-128 inhibitor), mimic $\mathrm{NC}+$ oe-NC group (urinary catheter perfusion with mimic $\mathrm{NC}$ and oe-NC lentivirus $0.2 \mathrm{~mL}$ ), miR-128 mimic + oe-NC group (urinary catheter perfusion with miR-128 mimic and oe-NC lentivirus $0.2 \mathrm{~mL}$ ), and miR128 mimic + oe-CB1 group (urinary catheter perfusion with miR-128 mimic and oe-CB1 $0.2 \mathrm{~mL}$ each). miR-128 mimic/inhibitor, oe-CB1 and nonsense NCs were purchased from Shanghai GenePharma Co., Ltd. (Shanghai, 
China) packaged with lentivirus, and the virus injection volume was $2 \times 10^{7} \mathrm{TU}$ (Shanghai Gima Pharmaceutical Technology Co., Ltd.). The ureter was ligated after perfusion, and the bladder perfusate was retained for $2 \mathrm{~h}$. At 12 weeks after STZ injection, rats in each group were examined for urodynamics. All rats had free access to water and were fed on a standard diet. This experimental procedure and animal use protocol have been approved by the Animal Ethics Committee.

\section{Urodynamic examination}

Urotan (1200 mg/kg body weight) was used for urodynamic examination under subcutaneous anesthesia. The midline incision was taken to expose the bladder, and a 27-gauge trocar was used to puncture the catheter through the top of the bladder. The intravesical catheter was connected to a baroreceptor (-Nihon Kohden, Japan) and a microperfusion pump (-JMS, Japan) through a three-way valve. The bilateral ureters were severed near the entrance to the bladder and the distal ends were ligated. Use up your bladder. After $30 \mathrm{~min}$ of stabilization, $37{ }^{\circ} \mathrm{C}$ physiological saline was infused into the bladder at a rate of $0.08 \mathrm{ml} / \mathrm{min}$, and a complete bladder manometry was performed. Record the bladder volume (the volume of physiological saline perfused until urination), the volume of single urination (the volume of vnysiological saline discharged through the urethral the maximum pressure in the bladder (the peris press in the bladder during urination), bladde nplianc, and disability urine volume (the amou't of ro ining normal saline aspirated through an $\mathrm{i}$ iravesical cacheter after urination). Calculate urination te $=$ uritiation volume $\times 100 \% /$ bladder volume. The ab in icators are the average of 3 experiments.

\section{Bladder specimen proc - SSI and IF, staining}

After urodynamic exa in ats were euthanized by $3 \%$ pentobarbita' sodiun 'D3761, Sigma, USA) anesthesia, the bladd er s removed, the surrounding fat and connective tissue $h$ removed, used paper to dry the bladder and the bladder, was weighed. The complete bladder crme was cut into the longitudinal muscle by of $t_{1}$ ladder sidewall in Krebs buffer. The musb) specimens were sectioned about $1 \mathrm{~mm}$ into 4\% raformaldehyde overnight, washed 3 times in PBS, shake, vigorously to wash the residual paraformaldehyde, and soaked in $70 \%$ alcohol solution overnight. After soaked in $80 \%$ and $90 \%$ alcohol solution for $1 \mathrm{~h}$, sections were immerse 3 times in 100\% alcohol for $1 \mathrm{~h}$ each time; xylene transparent 2 times for 8 min each time; immerse the wax in the oven at $65{ }^{\circ} \mathrm{C}$ (pre-melted) for $3 \mathrm{~h}$, embed in paraffin, and use Leica LM2300 Type paraffin microtome, cut into $5 \mu \mathrm{m}$ thick cross sections.
Sections were routinely dewaxed (3 times with xylene, $5 \mathrm{~min} /$ time) and hydrated (3 times with 100\% alcohol, $90 \%, 80 \%, 70 \%$ alcohol once, $5 \mathrm{~min} /$ time), rinsed under running water. After $10 \mathrm{~min}$ of nucleus staining by hematoxylin, the excess hematoxylin stain was washed away with tap water. And then the sections were separa ed by $1 \%$ hydrochloric acid alcohol for $5 \mathrm{~s}$, returned t blue by $1 \%$ ammonia for $5 \mathrm{~s}$, and then the sections wert with running water for $5 \mathrm{~min}$. After Eosin staini for $3 \mathrm{~min}$, the sections were treated with $90 \%$ ethanol for $5 \mathrm{~s}$ each, $100 \%$ ethator 3 th for 5 min each, xylene transparent treatm at 3 times or $5 \mathrm{~min}$ each, neutral gum seals, and then aced is a fume hood at room temperature and obs ed b, acroscopy.

\section{RT-qPCR}

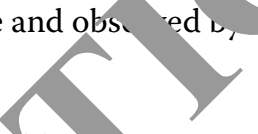

About $30 \mathrm{mg}$ of bladder. we was excised, and total RNA was extrarcea y Trizo! (15596026, Invitrogen, Car, Cal, USA) me d was reverse transcribed into cDNA according the instructions of the PrimeScript RT reage + (TakaRa Bio, Japan) reverse transcription kit. Primels we, designed and synthesized by Shanghai Sangon Biotech (Table 1). The reaction solution was tan for real-time quantitative PCR operation. The reaction s stem was $20 \mu \mathrm{l}: 10 \mu \mathrm{l}$ SYBR Premix, $2 \mu \mathrm{l}$ of cDNA wate, $0.6 \mu \mathrm{l}$ each of upstream and downstream primers, and $6.8 \mu \mathrm{l}$ of DEPC water. RT-qPCR experiments were performed using a 7500-type fluorescent quantitative PCR from American Applied Biosystems company. $2^{-\Delta \Delta \mathrm{Ct}}$ represented the doubling relationship of the target gene expression between the experimental group and the control group, the formula was as follows: $\Delta \mathrm{Ct}=\mathrm{CT}$ (target gene)-CT (internal reference), $\Delta \Delta \mathrm{Ct}=\Delta \mathrm{Ct}$ experimental group- $\Delta \mathrm{Ct}$ control group. $\mathrm{Ct}$ is the number of diffusion cycles that the real-time fluorescence intensity of the reaction reaches when the threshold is set. At this time, the diffusion increases in a logarithmic phase. The expression of miR-128 and CB1 in the cells was calculated.

\section{Western blotting}

About 100 mg of bladder tissue were lysed by RIPA lysate with a final concentration of $1 \mathrm{mM}$ phenylmethylsulfonyl fluoride (PMSF). Protein quantification was performed using the Bio-Rad DC Protein Assay Kit (Guangzhou

Table 1 Primer sequences used for RT-qPCR

\begin{tabular}{lll}
\hline Targets & Forward primer $\left(\mathbf{5}^{\prime} \mathbf{- \mathbf { 3 } ^ { \prime } )}\right.$ & Reverse primer $\left(\mathbf{5}^{\prime} \mathbf{- \mathbf { 3 } ^ { \prime } )}\right.$ \\
\hline miR-128 & CAGATCGTCACAGTGAACC & $\backslash$ \\
CB1 & CGTCTGAGGATGGGAAGGTA & TCTTGACCGTGCTCTTGATG \\
GADPH & CTTCACCACCATGGAGAAGGC & GGCATGGACTGTGGTCATGAG \\
\hline
\end{tabular}


Yuwei Biotechnology Instrument Co., Ltd., Guangzhou, China). Each sample was added SDS loading buffer. And boiling in water for $10 \mathrm{~min}$, the sample was load on a $10 \%$ SDS-polyacrylamide gel and run at $120 \mathrm{~V}, 30 \mathrm{~min}$, and $100 \mathrm{~V}$ for $90 \mathrm{~min}$. The protein was transferred from the gel to a PVDF membrane. The membrane was immersed in $1 \times$ TBST containing $5 \%$ skimmed milk powder and gently shaken at room temperature for $2 \mathrm{~h}$ to block non-specific binding sites. PVDF membrane was wash $1 \times$ TBST 3 times, $5 \mathrm{~min} /$ time. Add primary antibodies (anti-CB1, rabbit, 1: 250; Anti-NF-kB p65, rabbit, 1: 1000; anti-p-JNK, rabbit, 1: 1000; Abcam), incubated at $4{ }^{\circ} \mathrm{C}$ overnight, washed 3 times with $1 \times \mathrm{TBST}, 5 \mathrm{~min} / \mathrm{time}$, and then added with secondary antibody IgG (Affinity Biosciences Bio, S0001, goat anti-rabbit, 1: 20000) respectively and incubated 3 times with $1 \times$ TBST at room temperature for $1 \mathrm{~h}$. Development was performed with ECL. The gray value of Western blotting experimental protein expression was determined by Image J software, and the experiment was repeated three times.

\section{Dual luciferase report detection}

The biological prediction website was used to analyze the binding site of miR-128 and CB1, and obtain the fragment sequence containing the action site. The $3^{\prime}$ UTR region of CB1 was cloned and amplified Alto pmirGLO (E1330, Promega Corporation, USA) $\mathrm{Cl}^{\mathrm{c}}$ erase vector named pWt-CB1. pMut-CB1 y ctor s constructed, pRL-TK vector (E2241, Promes Corpora tion, USA) expressing Renilla luciferase yas con ucted, and mimic NC and miR-128 mimic, $\mathrm{n}-\mathrm{NC}$ and s, $-\mathrm{CB} 1$ were co-transfected with reporter ector (CRL-1415, ATCC, USA) into bladder epithelia ells $s$ V-HUC-1. Dual Luciferase Reporter Gene ' cay Kit (GM-040502A, Qcbio Science\&Technologies C.., China) was used to measure the fluores $a$ e int nsity at $560 \mathrm{~nm}$ (Firefly RLU) and $465 \mathrm{np}$ "Ren 1 RLU/, and the ratio of firefly RLU/renal RI wa sed to determine the binding intensity.

\section{RIP}

In the ment, the binding of miR-128, CB1 and Agr prot was detected according to the Magna RIP $\checkmark$ NA - indin! Protein Immunoprecipitation Kit (Merck M. "Dur, JSA). Lyse the cells with RIPA lysate for $5 \mathrm{~min}$ in a ce bath, and centrifugated at $4{ }^{\circ} \mathrm{C}$ for $10 \mathrm{~min}$ to remove the supernatant. Part of the cell extract was taken as input, and part was incubated with antibodies for coprecipitation. The specific steps were as follows: each co-precipitation reaction system was washed with $50 \mu \mathrm{L}$ magnetic beads, resuspended in $100 \mu \mathrm{L}$ RIP Wash Buffer, and $5 \mu \mathrm{g}$ of antibody was added according to the experimental grouping. The magnetic bead-antibody complex was washed and resuspended in $900 \mu \mathrm{L}$ RIP Wash Buffer, and $100 \mu \mathrm{L}$ of cell extract was added and incubated overnight at $4{ }^{\circ} \mathrm{C}$. The sample was placed on a magnetic holder to collect the magnetic bead-protein complex. Samples and Input were digested with proteinase $\mathrm{K}$ to extract RNA for subsequent PCR detection. Ago? was mixed at room temperature for $30 \mathrm{~min}$, and IgG vas used as a negative control.

\section{Statistical analysis}

SPSS 21.0 (IBM Corp., Armonk, N., US was used for statistical analysis. The $m \epsilon$ isurement data were expressed by mean \pm standard c iation, and the two sets of data were comparea sing anpaired design with normal distributio and $u$ corm variance, and an unpaired t test was ve Data co,nparison among multiple groups was perform using one-way analysis of variance (ANO A) ad Tukey's post hoc test. Data comparison betwee $\mathrm{rr}$ different time points was performed using rep ed measures ANOVA and post hoc testing w: rformed using Bonferroni. The relationship between tl e $\mathrm{cm}_{y}$ indicators was analyzed using Pearson correlation. The difference was statistically significant at

\section{$P>7$.

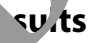 \\ mi. $\alpha-128$ is highly expressed in bladder tissues of DM modeled rats}

At $6 \mathrm{~W}$ and $12 \mathrm{~W}$ after STZ injection, 8 rats were randomly selected from each group for physiological characteristics observation. Compared with the NC group, the average blood glucose level of the rats in the DM group was significantly increased $(\mathrm{P}<0.05)$, while the blood glucose level of the rats in the PU group was not significantly changed (Fig. 1a), and that of the rats in the DM group was significantly higher than that of the PU group $(\mathrm{P}<0.05)$. Compared with the initial weight of the rats, the body weight of rats in the DM group was significantly lower than that of the NC group and the PU group during the same period $(P<0.05)$, while there was no significant difference in rat weight (Fig. 1b). Urine was collected through a metabolic cage. The results showed that compared with the NC group, the daily urine output of the rats in the PU group and the DM group was significantly increased $(P<0.05)$, and there was no significant difference between the PU group and the DM group (Fig. 1c) At the same time, there was no significant difference in the 24-h mean urine volume between $6 \mathrm{~W}$ and $12 \mathrm{~W}$ after STZ injection. After urodynamic examination, the bladder of each group was removed and weighed. As a result, compared with the NC group, the average weight of the bladder of rats in the PU group and the DM group increased significantly $(\mathrm{P}<0.05)$. There was no difference 


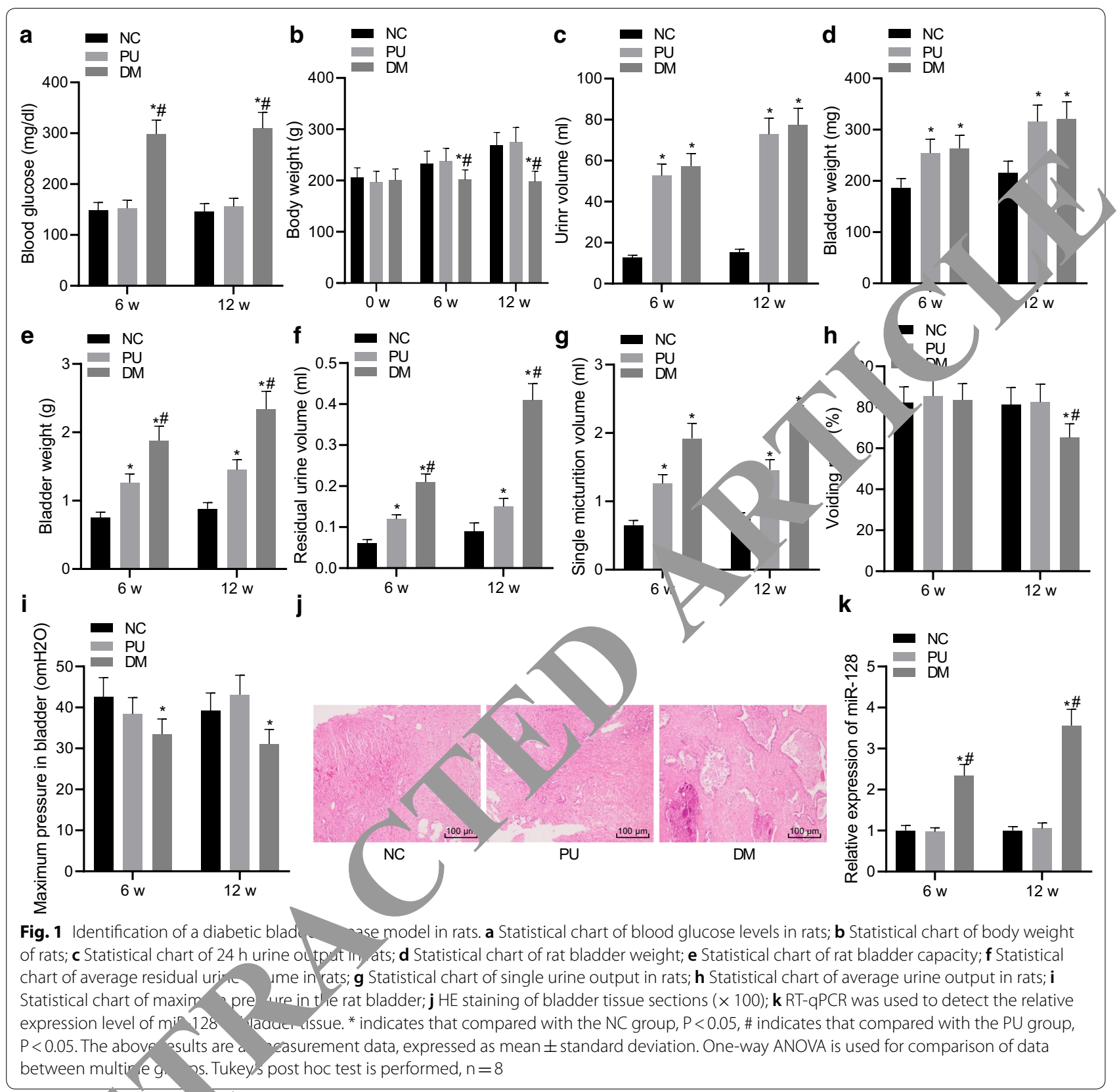

between PU group and the DM group, so was those a 6 6 and $1, W$ after STZ injection (Fig. 1d).

Th its of urodynamic testing under anesthesia sho d that when STZ induced DM at $6 \mathrm{~W}$ and $12 \mathrm{~W}$ (Fig. 1e), compared with the NC group, the bladder volume of the rats in the $\mathrm{PU}$ group and the $\mathrm{DM}$ group increased significantly $(\mathrm{P}<0.05)$ with the higher in the DM group $(P<0.05)$. In contrast to the $\mathrm{NC}$ group, the average residual urine of the PU group and the DM group rats was significantly increased $(\mathrm{P}<0.05)$. Compared with the PU group, the residual urine volume of the DM group was significantly increased $(\mathrm{P}<0.05)$, and it was further significantly increased at $12 \mathrm{~W}(\mathrm{P}<0.05)$ (Fig. 1f). At $6 \mathrm{~W}$ and $12 \mathrm{~W}$, diabetes was induced by STZ (Fig. 1g), the single-time urine output of the rats in the PU group was more than that in the $\mathrm{NC}$ group $(\mathrm{P}<0.05)$, and there was no significant difference compared with the single-time urine output of the DM group. The single-time urination volume at $6 \mathrm{~W}$ was significantly increased compared with the $\mathrm{NC}$ group $(\mathrm{P}<0.05)$, and the difference was not significant at $12 \mathrm{~W}$. The average urination rate results were shown in Fig. 1h. At 6 W, the average urination rate of 
rats in the DM and PU groups was not significantly different from that of the NC group. At $12 \mathrm{~W}$, the average urination rate of the DM group was significantly lower than that of the NC group $(\mathrm{P}<0.05)$. No significant difference was observed in the rate of urinary in the PU and $\mathrm{NC}$ group. At the same time, at $6 \mathrm{~W}$ and $12 \mathrm{~W}$, compared with the NC group, the maximum bladder pressure in the DM group was significantly lower than that in the PU group, but no significant difference was observed in the PU group (Fig. 1i).

The HE staining results showed that in rats of the NC group and the PU group, the muscle bundles of the detrusor transverse and longitudinal cuts were neatly arranged, the muscle bundles were tightly structured, the gap was filled with connective tissue, the nerve bundles were more common, and the smooth muscle cells were arranged neatly with tight intercellular structure. In the DM group, the detrusor muscle bundles was disordered, the structure was loose, the muscle bundles was broken, the gap between muscle bundles was significantly widened, edema, lymphocyte infiltration, collagen fibers between muscle bundles were reduced, small blood vessels were congested, nerve The bundles were visible, muscle cells atrophied (Fig. 1j).

In addition, RT-qPCR was used to detect the expression of miR-128 in bladder tissues of rats in each gr sup. The results showed that, under the same treatmer im miR-128 mRNA expression in bladder tissues of ra " $n$ the PU group and NC exhibited no signir nt diffe, ence, while the expression of miR-128 in slada tissue of rats in the DM group was signif antly highe than that of the NC group $(\mathrm{P}<0.05)$, a1 ( was significantly higher at $12 \mathrm{~W}$ than at $6 \mathrm{~W}(\mathrm{P}<0.05) \quad 1 \mathrm{k})$. The above results indicate that a rat diab is bladaer lesion model and a corresponding control moar. ve been successfully constructed, and th iR-1 8 is highly expressed in the bladder tissue of dial tic bladder lesion model rat, which may play a de in e occurrence of the lesion.

Inhibition of n.iR-1. ran improve the occurrence of diabet c bladder dis_ase in rats

In orke o tud the effect of miR-128 expression on blardor le ns /n DM rats, we selected a rat model i ject d with lentivirus. First, from the results of blood g. ise and weight measurement, it was found that compare ith the mimic NC group and the inhibitor NC group, the average blood glucose level of rats in the miR128 mimic group was increased $(\mathrm{P}<0.05)$, while that of rats in the 128 inhibitor group was reduced. There was no significant change in blood glucose levels between the mimic NC group and the inhibitor NC group (Fig. 2a). Compared with the weight of rats in the mimic $\mathrm{NC}$ group and inhibitor NC group, the weight of rats in the
miR-128 inhibitor group was increased, and that in miR128 mimic group was decreased compared with that of the mimic NC group $(\mathrm{P}<0.05)$ (Fig. 2b).

Urine was collected through a metabolic cage (Fig. 2c). Compared with the mimic NC group and inhibitor NC group, the daily urine output of rats in the miR-128 nhibitor group was significantly reduced, while inc eased in the miR-128 mimic group $(\mathrm{P}<0.05)$. The bladder ction of the mice in each group was subsequently exa by urodynamics, and the results show hat coinpared with the mimic NC group, $\mathrm{t}$ in the m 128 mi/group, bladder volume (Fig. 2d), average residual ur, ne volume (Fig. 2e), and single urination ve me (Fjg. 2f) all significantly increased $(P<0.65$, but $\quad 1$ urination rate (Fig. 2g) and maximum oladde ressure (Fig. 2h) were decreased in the $12 \mathrm{t}^{\mathrm{t}} \curvearrowright \mathrm{k}$ of $\mathrm{S}, \angle$ injection $(\mathrm{P}<0.05)$, while it was opposite in $\mathrm{ml} 128$ inhibitor group in comparison to the irnlb or NC gioup $(\mathrm{P}<0.05)$.

After urodyn ir ination, the bladder weight of each group of rat as excised and it was found (Fig. 2i) that com with the mimic NC group and inhibitor NC grcur, l, e bladder weight of rats in the miR-128 inhibitor gr bup was significantly reduced $(\mathrm{P}<0.05)$, and thi. in rats in the miR-128 mimic group significantly incre ed $(\mathrm{P}<0.05)$. The results of $\mathrm{HE}$ staining showed t $t$ compared with the mimic $\mathrm{NC}$ or inhibitor $\mathrm{NC}$ group, in the miR-128 mimic group, submucosal eosinophil infiltration was visible in the bladder wall, Severe mucous-like mucosa became smaller, swells, detrusor muscle cell morphology, size and disorder were arranged, smooth muscle tissue showed a large amount of collagen reduction and fiber dialogue, and interstitial fibrous tissue hyperplasia. In the miR-128 inhibitor group, detrusor muscle cells were arranged in an orderly manner, no significant degeneration of the myometrium was observed, and swelling was reduced (Fig. 2j). The above results indicate that overexpression of miR-128 can promote the occurrence of diabetic bladder disease in rats.

\section{miR-128 targets $\mathrm{CB} 1$ expression}

In order to study the targeting relationship of miR-128 in bladder epithelial cells, first, we jointly predicted the downstream target genes of miR-128 through the bioinformation website microT, TargetScan, miRWalk and RNAInter, and took the intersection of the four predicted results to obtain 51 candidate genes (Fig. 3a). The STRING website was used to analyze the interactions between 51 candidate genes and the results was visualized using Cytoscape 3.5.1. We found that ITPKC and CNR1 (CB1) were at the core of the interaction network diagram (Fig. 3b). Through the analysis of TargetScan website, we found that miR-128 can target CB1 and predicted the binding site (Fig. 3c). Then, the prediction 

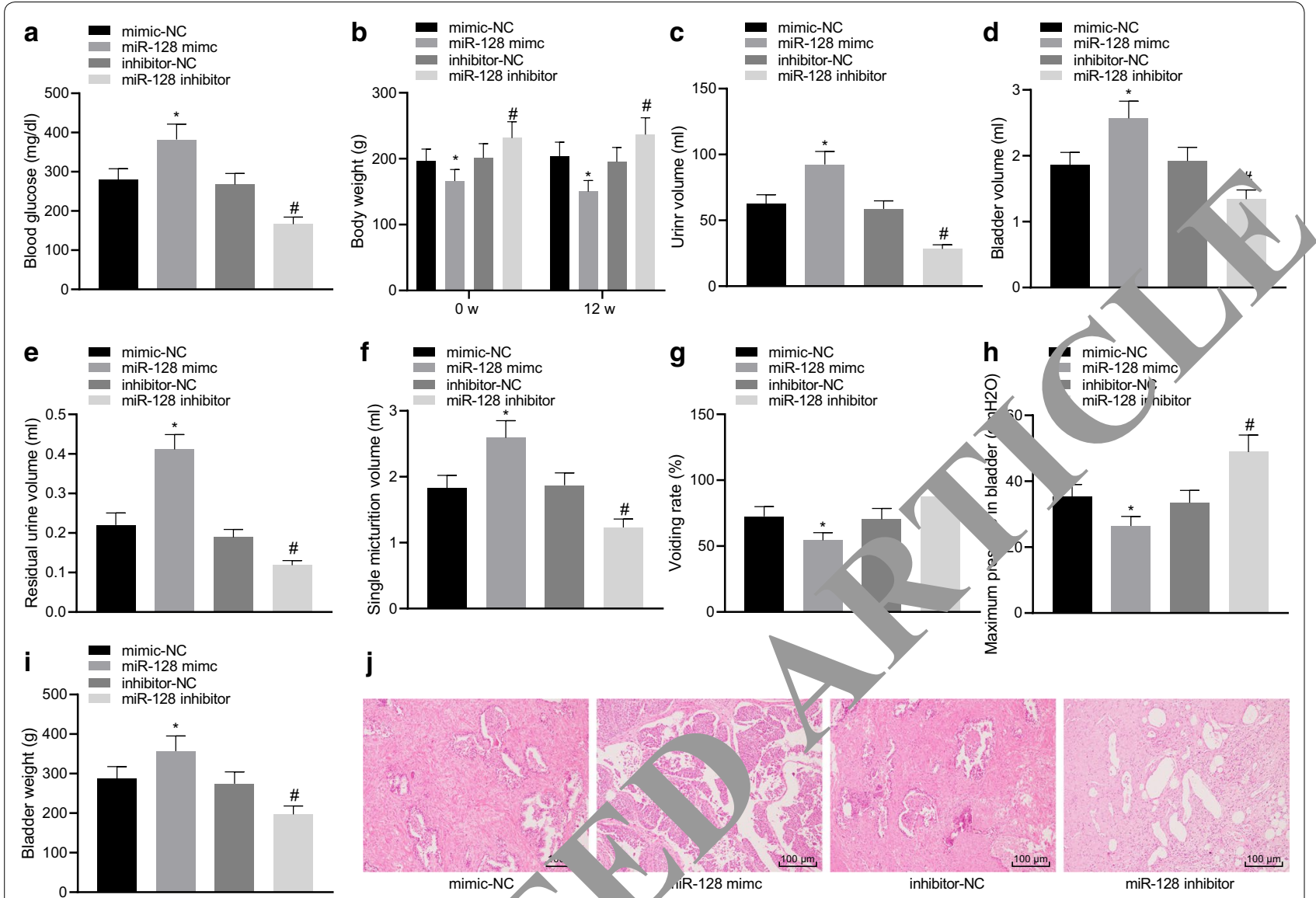

Fig. 2 Inhibition of miR-128 improves the occurrence or betic blad, er lesions in rats. a Statistical chart of blood glucose levels in rats; $\mathbf{b}$ Statistical chart of body weight of rats; $\mathbf{c}$ Statistical chart of 2 urine output in rats; $\mathbf{d}$ Statistical chart of rat bladder capacity; e Statistical chart of average residual urine output in rats; $\mathbf{f}$ Statistical chart of single ine output of rats; $\mathbf{g}$ Statistical chart of average micturition rate of rats; $\mathbf{h}$ Statistical chart of maximum pressure in the bladder of $\mathrm{ts}$; i Statistical chart of rat bladder weight). J Rat bladder tissue were observed by HE staining ( $x$ 100). * Indicates that compared with the mim $V$ c group $P<0.05$, \# indicates that compared with the inhibitor NC group $P<0.05$. The above results are measured data, expressed as mean \pm stand. inspection, $\mathrm{n}=8$

result of dual lucifes assay (Fig. 3d) showed that conpared the mimic NC group, the luciferase act , $\mathrm{h}$, of $\mathrm{CB1}$ Wt $3^{\prime} \mathrm{UTR}$ was inhibited by miR-128 ( $<0.05)$, hile CB1 Mut 3'UTR exhibited no change $(20.05)$. The results of RIP experiments showed that con ed $\mathrm{w}$ th IgG, both miR-128 and CB1 bound by 02, significantly increased, indicating that iR- 's can specifically bind CB1's 3'UTR region and do -regulates $\mathrm{CB} 1$ gene expression at post-transcriptiona evels (Fig. 3e).

Then, we used RT-qPCR to detect the expression of $\mathrm{CB} 1$ in the bladder tissues of each group of rats, and the results (Fig. 3f) showed that compared with the NC group and the PU group, CB1 was poorly expressed in the bladder tissues of rats of the DM group. Moreover, correlation analysis showed that miR-128 was negatively correlated with CB1 expression in bladder tissues of
DM rats (Fig. 3g). Subsequently, by interfering with the expression of miR-128, we used RT-qPCR and Western blotting to detect the mRNA and protein expression of CB1 in the bladder tissues of rats in each group (Fig. 3hj). Compared with the mimic NC group, the mRNA and protein expression levels of CB1 in the miR-128 mimic group were significantly reduced $(\mathrm{P}<0.05)$. Compared to the inhibitor NC group, the mRNA and protein levels of CB1 in the miR-128 inhibitor group were significantly increased $(\mathrm{P}<0.05)$. In diabetic bladder disease tissues, miR-128 can target down-regulation of CB1 expression.

\section{miR-128 targets CB1 to regulate the occurrence of diabetic bladder disease}

To study the role of CB1 expression in the development of diabetic bladder disease, we divided the DM rats into the following three groups for injection treatment: 


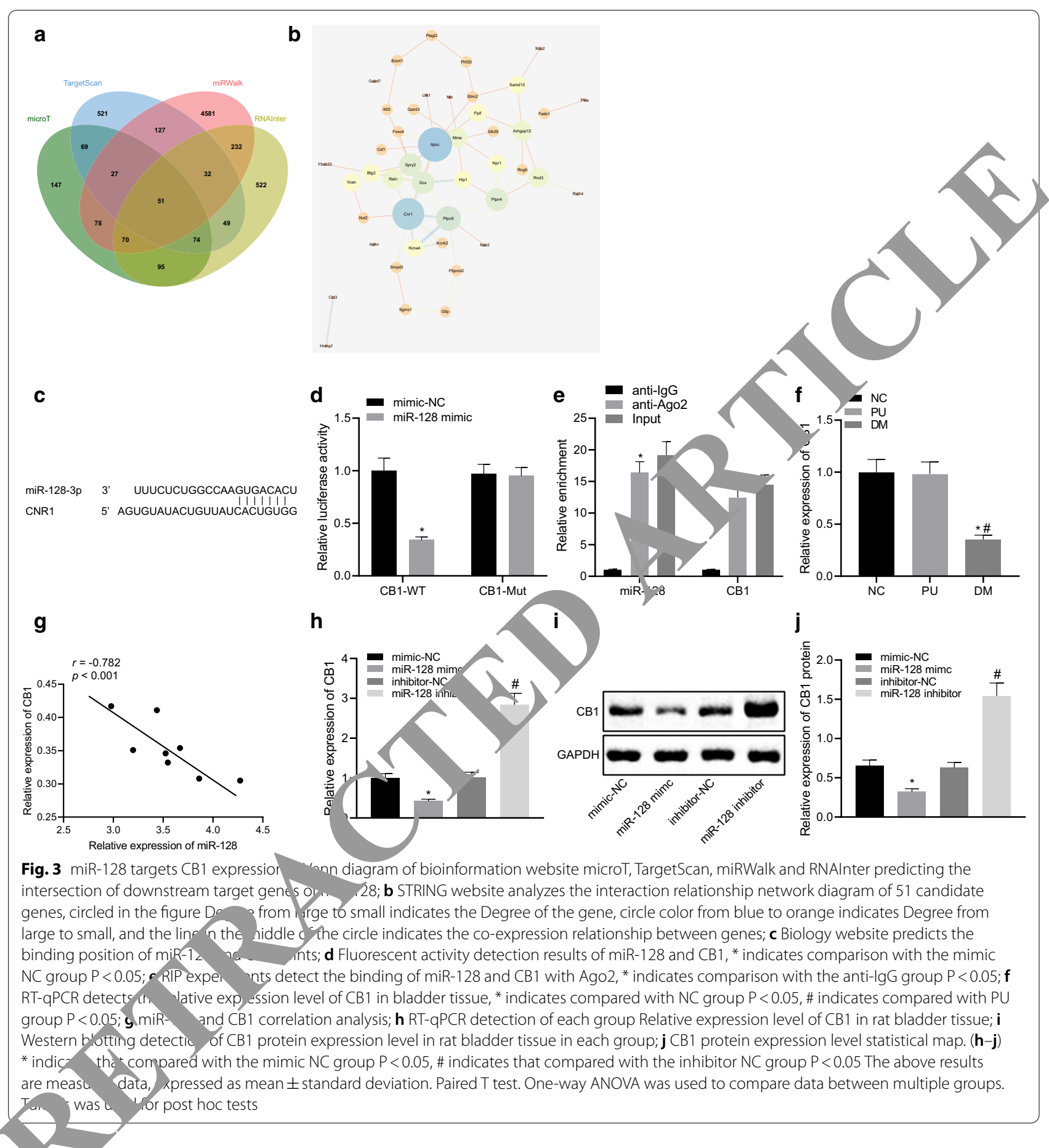

mimic $\mathrm{NC}+$ oe-NC group, miR-128 mimic + oe-NC group and miR-128 mimic + oe-CB1 group. qPCR was used to detect the expression of miR-128 in bladder tissues of rats in each group, qPCR and Western blotting were used to detect the expression of CB1 mRNA and protein in bladder tissues of rats in each group. Compared with the mimic $\mathrm{NC}+$ oe- $\mathrm{NC}$ group, in the bladder tissues of rats in the miR-128 mimic + oe-NC group, the expression of miR-128 significantly increased $(\mathrm{P}<0.05)$ (Fig. 4a), and the mRNA and protein expression of $\mathrm{CB} 1$ significantly decreased $(\mathrm{P}<0.05)$ (Fig. 4b, c). Compared with miR-128 mimic + oe-NC group, miR-128 mimic + oe-CB1 group had no significant change in miR-128 expression, and CB1 mRNA 


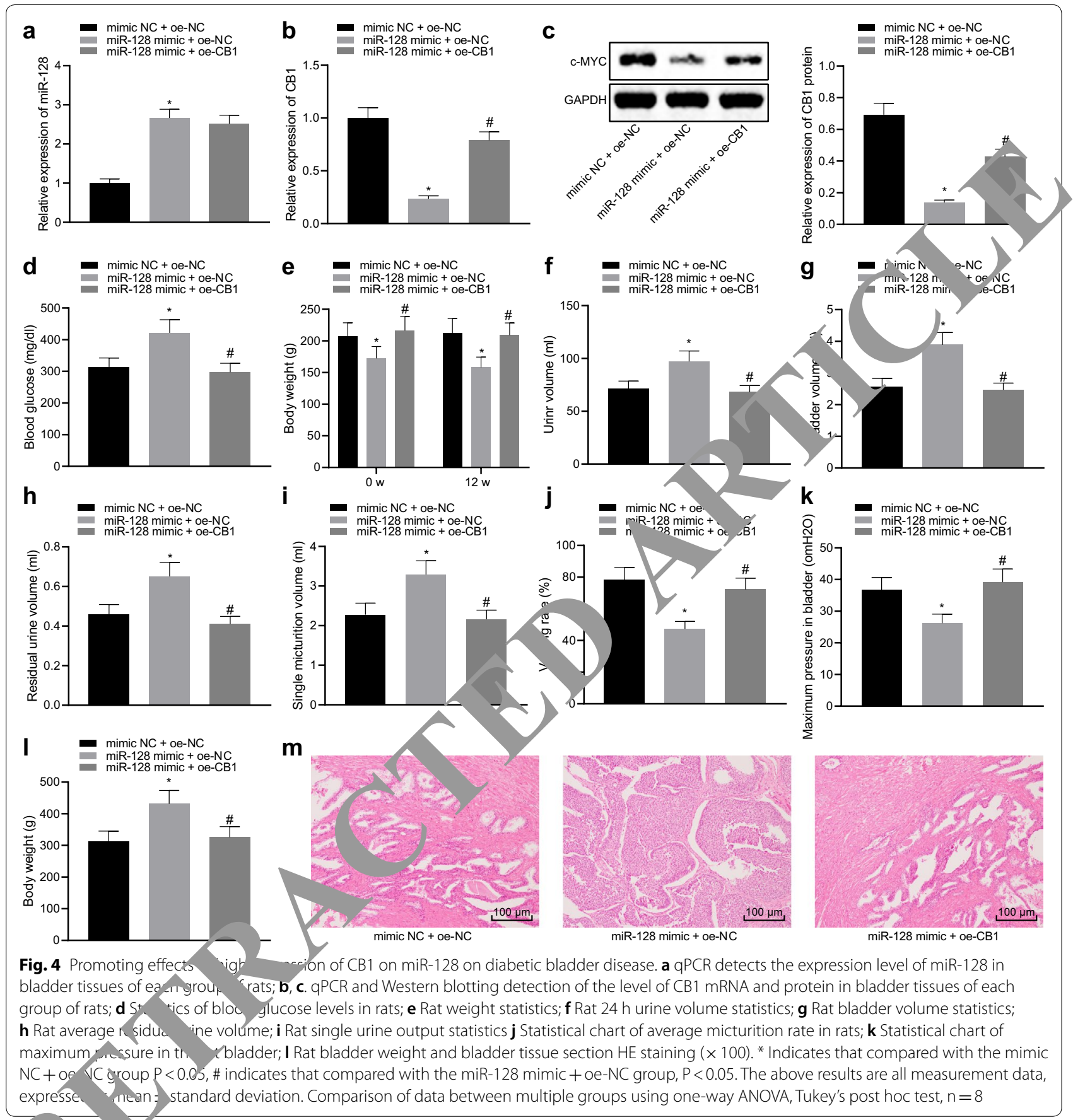

ana otein expression increased significantly $(\mathrm{P}<0.05)$ (Fig. + b, c).

According to the results of blood glucose and weight measurement, it was found that compared with the mimic $\mathrm{NC}+$ oe-NC group, the average blood glucose level of rats in the miR-128 mimic + oe-NC group was significantly increased at the same experimental time $(\mathrm{P}<0.05)$ (Fig. 4d), and the body weight was significantly reduced
$(\mathrm{P}<0.05)$ (Fig. 4b). In the miR-128 mimic + oe-CB1 group, the blood glucose level of the rats was significantly reduced $(\mathrm{P}<0.05)$ (Fig. $4 \mathrm{a})$, and the body weight was significantly increased $(\mathrm{P}<0.05)$ (Fig. 4e). Urine was collected through a metabolic cage, and the results showed that compared with the mimic $\mathrm{NC}+$ oe- $\mathrm{NC}$ group, the daily urine output of rats in the miR-128 mimic + oe-NC group was significantly increased $(\mathrm{P}<0.05)$. And in the 
(See figure on next page.)

Fig. 5 miR-128 regulates NF-KB/p-JNK axis through CB1 to affect the occurrence of diabetic bladder disease. a STRING website analysis of gene interaction network diagram; b-d Western blotting detection of NF-KB and p-JNK and apoptosis in bladder tissue of three groups of NC, PU and DM rats Expression of related protein $\mathrm{BCl} 2{ }^{*}{ }^{*}$ indicates compared with NC group $\mathrm{P}<0.05$; e Western blotting detected NF-KB in rat bladder tissue of mimic NC group, miR-128 mimic group, inhibitor NC group and miR-128 inhibitor group, P-JNK and apoptosis-related protein Bcl2 expression, * indicates compared with mimic NC group P<0.05, \# indicates compared with inhibitor NC group P $<0.05$; $\mathbf{f}$ Expression of NF-KB, p-JNK and apoptosis-related protein Bcl2 in bladder tissue of rats in each group by Western blotting, ${ }^{*}$ indicates compared with the mimic NC+ oe-NC orusp $\mathrm{P}<0.05$, \# indicates compared with the miR-128 mimic + oe-NC group $\mathrm{P}<0.05 . \mathbf{g}$ qPCR was used to detect the expression level of miR-12 bladder tissue of rats in each group, ${ }^{*}$ indicates compared with mimic NC+DMSO group $P<0.05 ; \mathbf{h}$ qPCR detection of CB1 expression in $b$ tissues of rats in each group, ${ }^{*}$ indicates compared with mimic NC+DMSO group $\mathrm{P}<0.05$; $\mathbf{i}$ Western blotting detection of CB1, NF-KB, p-JNK a apoptosis-related protein $\mathrm{BC} 22$ in rat bladder tissue of each group Expression, * indicates compared with the mimic NC+DMSO \# indicates compared with the miR-128 mimic + DMSO group P $<0.05 ; \mathbf{j}$ statistical map of blood glucose levels in rats; $\mathbf{k}$ statistical weights in rats; $\mathbf{I} 24 \mathrm{~h}$ urine volume statistics of rats; $\mathbf{m}$ bladder volume statistics of rats; $\mathbf{n}$ Statistics chart of average resid $\mathbf{a l}$ urine volu. in rats; - Statistics chart of single urine output of rats; $\mathbf{p}$ Statistics chart of average urine output of rats; $\mathbf{r}$ Rat bladder weight stat tics; $\mathbf{s}$ Bladder (issue section HE staining $(\times 100)$. Figure $\mathbf{j}-\mathbf{r}$, ${ }^{*}$ indicates the comparison with mimic NC+DMSO group $P<0.05$, \# indicates th ompariso 1 with miR-128 mimic + DMSO group $P<0.05$. The above results are all measurement data, expressed as mean \pm standard deviat One An OVA and Tukey's post hoc test was used to compare data between multiple groups

miR-128 mimic + oe-CB1 group, the daily urine volume of rats was significantly reduced $(\mathrm{P}<0.05)$ (Fig. 4f).

Subsequently, the bladder function of the mice in each group was examined by urodynamics. The results showed that, compared with the mimic $\mathrm{NC}+$ oe-NC group, in the miR-128 mimic + oe-NC group at 12 weeks of STZ injection, the mean maximum bladder volume, mean residual urine volume, and single voiding capacity al increased significantly $(\mathrm{P}<0.05)$, and the maximum $\mathrm{b}^{1}$. $\mathrm{d}$ der pressure and mean micturition rate were rnifcantly reduced $(\mathrm{P}<0.05)$. Compared with the mil 8 mimic + oe-NC group, the mean maximum dder vo ume (Fig. 4g), average residual urine vol. me "o. 4h), and single micturition volume (Fig. 11 ) in rats $\alpha$ the 128 mimic + oe-CB1 group all sig, ficantly decreased $(\mathrm{P}<0.05)$, and the maximum press in the bladder (Fig. 4j) and the mean micturition rate was significantly increased $(\mathrm{P}<0.05)$ (Fig. 4k). F I w odynamic examination, the bladder we + of $\mathrm{c}$ ach group of rats was excised and it was fo $\mathrm{nd} t$ at cor pared with the mimic $\mathrm{NC}+$ oe-NC grow th nin-1 $\angle 8$ mimic + oe-NC group had significant increas $y$ bladder weight $(\mathrm{P}<0.05)$. Compared $w_{4} \cdot \mathrm{h}_{\mathrm{s}}$ miR-128 mimic + oe-NC group, the bladder welght of rat $\mathrm{C}$ miR-128 mimic + oe-CB1 group was sig 'ca tly reduced $(\mathrm{P}<0.05)$.

The res $\mathrm{o}$ - HE staining showed that compared v th he milc $\mathrm{NC}+$ oe-NC group, in the miR-128 1. NC group, the detrusor muscle bundles were disc sred and loose, the muscle bundles were broken, and the gap between the muscle bundles was significantly widened, and urinary muscle cells atrophy, diverse morphology, lymphocyte infiltration, a large number of vacuolar degeneration, a small amount of eosinophilic degeneration, and increased interstitial and collagen components were observed. Compared with the miR-128 mimic + oe-NC group, in the miR-128 mimic + oe- CB1 group, the detruson uscle b, ndles were arranged neatly, the structure ${ }_{2}$ tis the gap was filled with connective tissue, the muscl olls were vacuolated and the lymphocytes wer infiltrate, (Fig. 4l). The above results indicate that high exy ion of CB1 antagonizes the effect of miR-128 on the development of diabetic bladder disease.

\section{miR- 8 regulates NF-KB/p-JNK axis through CB1 to affect o currence of diabetic bladder disease}

In order to further study the regulatory mechanism of niR-128 on the occurrence of diabetic bladder disease through CB1, we found 414 genes related to diabetic bladder disease through the GeneCards database, analyzed the gene interaction using the STRING website, and found the gene NF-KB (NFKB1) can regulate p-JNK (MAPK8) to affect diabetic bladder disease (Fig. 5a). The co-expression relationship between $\mathrm{CB} 1$ and NF-KB in blood was obtained through the website Chipbase v2.0 (Fig. 5b), and the co-expression relationship between NF-KB and p-JNK (Fig. 5c). We know from the literature that CB1 can inhibit the activation of NF-KB [21], and NF-KB can promote the occurrence of diabetic bladder disease [22], and at the same time can promote the activation of JNK (p-JNK) [23] and activate JNK (p-JNK) can promote the occurrence of diabetic bladder disease by positively regulating apoptosis [24]. Therefore, we next explored that in the diabetic bladder, miR-128 regulates the NF-KB/p-JNK axis through CB1.

First, we detected the expression of NF-KB, p-JNK, and apoptosis-related protein $\mathrm{Bcl} 2$ in bladder tissue of NC, PU, and DM groups by Western blotting. The results showed that compared with the NC group, expressions of NF-KB p50, p-JNK and $\mathrm{Bcl} 2$ in the bladder tissues of the rats in the PU group were not significantly changed, but increased in the bladder tissues of rats in the DM group $(\mathrm{P}<0.05)$ (Fig. 5d). Western blotting revealed that 


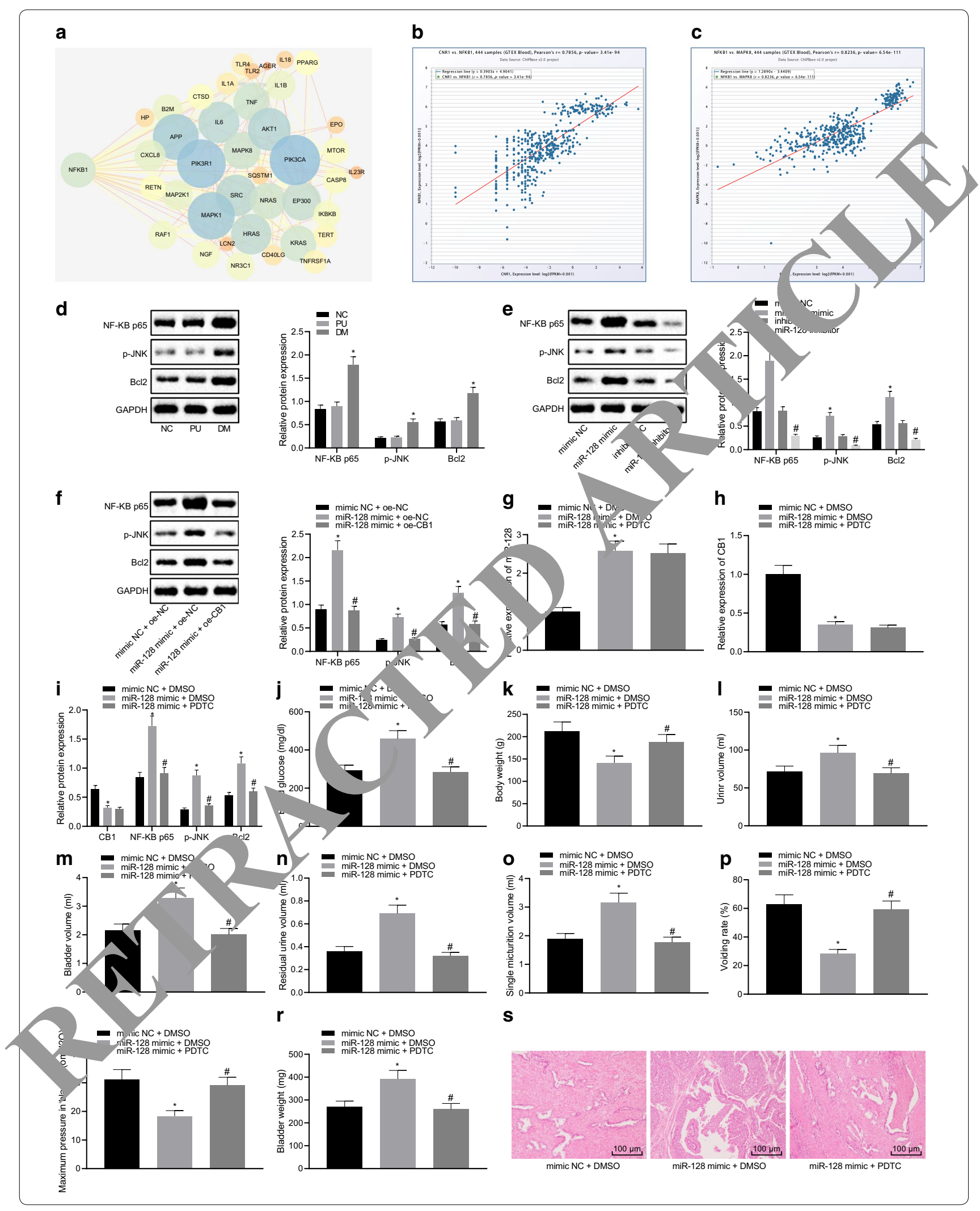


compared with the inhibitor NC group, the expression of NF-KB p50, p-JNK and Bcl2 in the bladder tissues of rats in miR-128 mimic group significantly increased, but that in the miR-128 inhibitor group were decreased $(\mathrm{P}<0.05)$ (Fig. 5e). Moreover, compared with the miR128 mimic + oe-NC group, the expression of NF-KB p50, $\mathrm{p}-\mathrm{JNK}$ and $\mathrm{Bcl} 2$ were significantly decreased in the miR128 mimic + oe-CB1 group $(\mathrm{P}<0.05)$ (Fig. 5f). The above results indicate that miR-128 can regulate the expression of NF-KB and p-JNK through CB1 in the diabetic bladder and affect the level of apoptosis.

Further, after treated with miR-128 mimic, rats were simultaneously injected with NF-KB inhibitor PDTC, and Western blotting was used to detect NF-KB, p-JNK and apoptosis-related protein $\mathrm{Bcl} 2$ in bladder tissues of each group of rats expression. Rats were examined with urodynamics, and bladder tissue staining was performed. Compared with the mimic NC+DMSO group, in the bladder tissues rats in the miR-128 mimic + DMSO group, the expression of miR-128 increased significantly $(\mathrm{P}<0.05)$ (Fig. 5g), mRNA and protein expression of CB1 was significantly reduced $(\mathrm{P}<0.05)($ Fig. $5 \mathrm{~h}, \mathrm{i})$, and levels of NF-KB, p-JNK and $\mathrm{Bcl} 2$ were significantly increased $(\mathrm{P}<0.05)$ (Fig. $5 \mathrm{i})$, the mean blood glucose level was significantly increased $(\mathrm{P}<0.05)$ (Fig. $5 \mathrm{j})$, weight was significantly reduced $(\mathrm{P}<0.05)$ (Fig. $5 \mathrm{k})$, and the daily vinte output was significantly increased $(\mathrm{P}<0.05)$ (Fig. $D$ ar $d$ the average maximum bladder volume (Fig. $5 \mathrm{~m}$, ave e residual urine volume (Fig. 5n), single urin $\ldots$ volum (Fig. 5o) increased significantly $(\mathrm{P}<0.05, \mathrm{~m}$ micturition rate (Fig. $5 \mathrm{p}$ ) and maximur bladder pl ssure (Fig. 5q) decreased significantly (Fig $5 \mathrm{~m})\left(\mathrm{P}_{5} 0.05\right)$, the bladder weight increased significantl $>\quad<0.05$ ) (Fig. 5r). Compared with the miR-128 + MSO group, in the miR128 mimic + PDTC group, the ex sion of miR-128 and CB1 were not signi that changed in rat bladder, the expression of NF-KP -JI < and apoptosis-related protein Bcl2 were sionific ly reduced $(\mathrm{P}<0.05)$ (Fig. 5i), and the body of of $\mathrm{r}_{\mathrm{c}} \mathrm{s}$ was significantly increased $(\mathrm{P}<0.05)$ (Fig. 5k), he average blood glucose level. Significantly decreased $P^{2}<0.05$ ) (Fig. 5j), daily urine output was fica tly reduced $(\mathrm{P}<0.05)$ (Fig. 5l), average marnum ad a volume (Fig. $5 \mathrm{~m}$ ), average residual rine olum (Fig. 5n), single urine output (Fig. 5o) were St. Tlicancy decreased $(P<0.05)$, mean urination rate (Fig. $)$ and maximum bladder pressure (Fig. 5q) were significantly increased $(\mathrm{P}<0.05)$, and bladder weight was significantly reduced $(\mathrm{P}<0.05)(\mathrm{Fig} .5 \mathrm{r})$.

The results of HE staining showed that compared with the mimic NC+DMSO group, the detrusor muscle bundles in the miR-128 mimic + DMSO group were disordered and loose, the muscle bundles were broken, the space between muscle bundles was significantly widened and edema, and the detrusor muscle cells atrophied, with diverse morphology, lymphocyte infiltration, and a large number of vacuolar degeneration observed. Compared with the miR-128 mimic + DMSO group, in the miR-128 mimic + PDTC group, detrusor muscle bundles were arranged more neatly, the structure was tight, and the gap was filled with connective tissue, with vascular $d$ egeneration of muscle cells and a small amount of lyn ocyte infiltration found (Fig. 5s). The above results indica bat miR-128 regulates the NF-KB/p-JNK a throus $h$ CB1 and affects the occurrence of diabeti dada dis ase.

\section{Discussion}

Many miRNAs have been fo to to Important roles in DCP by regulating cytokin and then regulating tumor cell proliferation, etastas, s, invasion and apoptosis. The role of miRNA $n$ cancer development has not been elucidate and the role of miR-128a expression in diabete., the corresponding regulatory mechanisms and wnstream regulatory signals need further st Fven though the study of HIV-1 found that anti-miR-128 pu cially neutralized IFN-mediated HIV-1 blockade ar d elucidated the mechanism by which miR12. npairs HIV-1 replication may provide new candidates or the development of therapeutic intervention -1. And studies have shown that miR-128 levels are el vated in benign prostate epithelial cell lines compared to invasive prostate cancer cells. Knockdown of miR-128 can induce benign prostate epithelial cell infiltration, while overexpression of miR-128 attenuates infiltration of prostate cancer cells [26]. It has been reported that proneuron miR-128 is a candidate miRNA for glioma tumor suppressor. Reduced miR-128 expression is associated with aggressive human glioma subtypes. miR-128 has a tumor suppressive effect. miR-128 inhibits giNSC growth by enhancing neuronal differentiation. miR-128 inhibits growth and mediates differentiation by targeting oncogenic receptor tyrosine kinase (RTK) epithelial growth factor receptor and platelet-derived growth factor receptor alpha. [12] miR-128 is a glioma tumor suppressor that targets RTK signaling to inhibit giNSC self-renewal and enhance differentiation [27]. These results suggest that miR-128 plays a key role in DCP.

The miR-128 precursor can promote cell proliferation and inhibit apoptosis. Compared with the lnc-LAMC2-1: $1 \mathrm{rs} 2147578 \mathrm{C}$ allele, the $\mathrm{G}$ allele increases the risk of ovarian cancer by reducing the binding between lncLAMC2-1: 1 and miR-128-3p, thereby further reducing DCC and inhibition of apoptosis [28]. Myostatin (MSTN) inhibits excessive cardiac autophagy by blocking AMPK/ mTOR and miR-128/PPAR $\gamma / \mathrm{NF}-\mathrm{kB}$ signaling pathways, at least partially significantly inhibiting pathological cardiac hypertrophy and dysfunction [29]. miR-128 
can regulate the role and mechanism of glioma tumor angiogenesis through the miR-128/p70S6K1 axis, and miR-128 may become a potential therapeutic target for glioma in the future [13]. We predict that miR-128 targets the regulation of CB1 expression through bioinformatics, and through our findings, we found that miR-128 is highly expressed in the bladder tissue of diabetic bladder disease rats, and may play a role in the occurrence of lesions, And we found that by effectively inhibiting miR128 , we can improve the occurrence of diabetic bladder disease in rats. This is related to the abnormal expression of miRNAs (such as miR-128 and miR-21) in gliomas. In addition, there are reports in the literature that miR-128 is related to the proliferation of glioma cells, and that it reduces the expression of miR-10b [30], which can cause cell apoptosis. Existing studies have shown that miR-128 is highly expressed in central nervous cells but low in malignant gliomas. MiR-128 is a direct-acting target of P53 [31] and can interact with cyclins CDK6, BCL-2 and E2F3 form a complex that inhibits the translation of the target gene or degrades the miRNA of the target gene, induces the cell cycle to stagnate in the $S$ phase, resulting in apoptosis and senescence [14]. These results suggest that we have a deeper understanding of miR-128. We adopt miR-128 inhibition to significantly improve the occurrence of diabetic bladder disease in rats and we have found for the first time that miR-128 car $\mathrm{rg}+$ the inhibition of CB1 expression. Previous sty aies shown that CB1 can cause Inflammation, is mmatio, plays an important role in the development or ibetes [27]. Our high expression of CB1 can ntagonize th $<$ promotion of miR-128 on the occurren e of diabetic bladder disease. qPCR and Western blo w re used to detect the expression levels of $1 \mathrm{mRNA}$ and protein in bladder tissue of rats in each grpur. mpared with the mimic $\mathrm{NC}+$ oe-NC gr mik 128 increased expression (Fig. 4a), CB1 n NA and p\%otein expression levels significantly decrsased. B1 mRNA and protein expression levels dec ed sign cantly (Fig. 4b, c), compared with miR-12 $\mathrm{mi}$ +oe-NC group, bladder tissue of rat was $n 0$ significan, change in miR-128 expression, and mRNA 1 cote in expression levels of CB1 significantly incmsed $4 \%, \mathrm{c}$ ). CB1 and our results show that miR$28 \mathrm{~h} \mathrm{~s}$ sign icant regulatory role. Such results suggest th. III -ne diabetic bladder, miR-128 may regulate the expl ion of signaling pathways NF-KB and p-JNK by regulating $\mathrm{CB} 1$. Previous studies have investigated the role of CB1 receptors in mediating 2-AG neuro protection. The findings suggest that 2-AG exerts its neuroprotective effect at least in part after $\mathrm{CHI}$ through the CB1 receptor-mediated mechanism, which involves inhibiting intracellular inflammatory signaling pathways [21]. Compared with previous studies, our research found that
miR-128 regulates the NF-KB/p-JNK axis through CB1 to affect the occurrence of diabetic bladder disease.

\section{Conclusion}

In summary, we report for the first time that miR-128 regulates the NF-KB/p-JNK axis through CB1 to iffect the occurrence of diabetic bladder disease. W suggest further research on drugs with similar pharn. $10 \mathrm{i}$ cal characteristics to lay a theoretical foundation. $\mathrm{n}$ in-depth understanding of the pathoge is of diabetic bladder disease and for finding new/nerap tic /argets.

\section{Abbreviations}

DCP: Diabetic cystitis; DM: Diabetic Mellit YC: Nomal control; STZ: Streptozotocin; PMSF: Phenylmethylsulfo iyl fluoride VOVA: Analysis of variance.

Acknowledgements

We would like to acknowlodge the rev 2 s for their helpful comments on this study.

\section{Authors' contributio}

$X G$ and JW wrote the pap $1 / 4$ and YW conceived and designed the experiments; TY an alyzed the data; GL and KF collected and provided the sample for this stury.y. authors read and approved the final manuscript.

\section{Funding}

This $k$ was supported by the Yunnan Provincial Science and Technology

Depar ent (No. 2017FE467(-059)); National Natural Science Foundation

Chin (No. 81860127); Medical Discipline Leaders of Health and Family

P. 19 Commission of Yunnan Province (No. D-201615); Young and MiddleAged Academic and Technical Leaders Reserved Scholar of Yunnan Province No. 2017FB038); the Engineering and Research Center of Yunnan College and University for Female Pelvic Floor Disease Diagnosis and Treatment.

\section{Availability of data and materials}

The authors confirm that the data supporting the findings of this study are available within the article.

\section{Ethics approval and consent to participate}

This experimental procedure and animal use protocol have been approved by the Animal Ethics Committee of the Second Affiliated Hospital of Kunming Medical University.

\section{Consent for publication}

Not applicable.

\section{Competing interests}

The authors declare no conflicts of interest.

\section{Author details}

${ }^{1}$ Department of Urology, The Second Affiliated Hospital of Kunming Medical University, No. 374, Dianmian Dadao, Kunming, Yunnan 650101, People's Republic of China. ${ }^{2}$ Department of Biochemistry and Molecular Biology, The Primary Medicine School of Kunming Medical University, Kunming 650101, People's Republic of China. ${ }^{3}$ Department of Urology, The 2 nd Hospital of Kunming Medical University, Kunming 650101, People's Republic of China.

Received: 21 April 2020 Accepted: 5 June 2020

Published online: 16 July 2020

\section{References}

1. Yang S, Wang D, Cao X, Zhang X, Yuan X, Yang T, et al. Store operated calcium channels are associated with diabetic cystopathy in streptozotocin induced diabetic rats. Mol Med Rep. 2018;17(5):6612-20. 
2. Cheng YJ, Imperatore G, Geiss LS, Wang J, Saydah SH, Cowie CC, et al. Secular changes in the age-specific prevalence of diabetes among U.S. adults: 1988-2010. Diabetes Care. 2013;36(9):2690-6.

3. Kaplan SA, Te AE, Blaivas JG. Urodynamic findings in patients with diabetic cystopathy. J Urol. 1995;153(2):342-4.

4. Sasaki K, Chancellor MB, Phelan MW, Yokoyama T, Fraser MO, Seki S, et al. Diabetic cystopathy correlates with a long-term decrease in nerve growth factor levels in the bladder and lumbosacral dorsal root Ganglia. J Urol. 2002;168(3):1259-64.

5. Hanna-Mitchell AT, Ruiz GW, Daneshgari F, Liu G, Apodaca G, Birder LA. Impact of diabetes mellitus on bladder uroepithelial cells. Am J Physiol Regul Integr Comp Physiol. 2013;304(2):R84-93.

6. Wang D, Yuan X, Hu C, Zhang B, Gao H, Wang D, et al. Endoplasmic reticulum stress is involved in apoptosis of detrusor muscle in streptozocininduced diabetic rats. Neurourol Urodyn. 2017;36(1):65-72.

7. Harfe BD. MicroRNAs in vertebrate development. Curr Opin Genet Dev. 2005; 15(4):410-5.

8. Ambros $V$. The functions of animal microRNAs. Nature. 2004;431(7006):350-5

9. Esquela-Kerscher A, Slack FJ. Oncomirs-microRNAs with a role in cancer. Nat Rev Cancer. 2006;6(4):259-69.

10. Li M, Fu W, Wo L, Shu X, Liu F, Li C. miR-128 and its target genes in tumorigenesis and metastasis. Exp Cell Res. 2013;319(20):3059-64.

11. Godlewski J, Nowicki MO, Bronisz A, Williams S, Otsuki A, Nuovo G, et al. Targeting of the Bmi-1 oncogene/stem cell renewal factor by microRNA-128 inhibits glioma proliferation and self-renewal. Cancer Res. 2008;68(22):9125-30.

12. Papagiannakopoulos T, Friedmann-Morvinski D, Neveu P, Dugas JC, Gill RM, Huillard E, et al. Pro-neural miR-128 is a glioma tumor suppressor that targets mitogenic kinases. Oncogene. 2012;31(15):1884-95.

13. Shi ZM, Wang J, Yan Z, You YP, Li CY, Qian X, et al. MiR-128 inhibits tumor growth and angiogenesis by targeting p70S6K1. PLOS ONE. 2012;7(3):e32709.

14. Zhang Y, Chao T, Li R, Liu W, Chen Y, Yan X, et al. MicroRNA-128 inhibite glioma cells proliferation by targeting transcription factor E2F3a. J $\mathrm{Nol}$ Med (Berl). 2009;87(1):43-51.

15. Chen S, Li P, Li J, Wang Y, Du Y, Chen X, et al. MiR-144 inhibits and induces apoptosis and autophagy in lung cancer cel' 'vy targetins TIGAR. Cell Physiol Biochem. 2015;35(3):997-1007.

16. Zhao M, Huang J, Gui K, Xiong M, Cai G, Xu J, et al. The downre ation of miR-144 is associated with the growth and in asion of osteosa coma cells through the regulation of TAGLN e ression. Int J Mol Med. 2014;34(6):1565-72.

17. Cao T, Li H, Hu Y, Ma D, Cai X. miR-144 suppress onro reration and metastasis of hepatocellular carcinom hy targeting [2F3. Tumour Biol. 2014;35(11):10759-64.

18. Guan H, Liang W, Xie Z, Li H, Liu J, Liu L, t $=1$. Do, vn-regulation of miR-144 promotes thyroid cancer c- in in by targeting ZEB1 and ZEB2. Endocrine. 2015;48(2):566-7/$$
2 \text { i }
$$

19. Guo Y, Ying L, Tian Y, Yang P, Zhu Y, Wang Z, et al. miR-144 downregulation increases bladder cancer cell proliferation by targeting $\mathrm{EZH} 2$ and regulating Wnt signaling. FEBS J. 2013;280(18):4531-8.

20. Iwaya T, Yokobori T, Nishida N, Kogo R, Sudo T, Tanaka F, et al. Downregulation of miR-144 is associated with colorectal cancer progression via activation of mTOR signaling pathway. Carcinogenesis. 2012;33(12):2391-7.

21. Panikashvili D, Mechoulam R, Beni SM, Alexandrovich A, Shohami E. CB cannabinoid receptors are involved in neuroprotection via NF-k? na B inhibition. J Cereb Blood Flow Metab. 2005;25(4):477-84.

22. LiWJ, Shin MK, Oh SJ. Poly(ADP-ribose) polymerase is invol development of diabetic cystopathy via regulation of nuclear $t$

kappa B. Urology. 2011;77(5):1265 e1-8. 3. Liu J, Yang D, Minemoto Y, Leitges M, Rosner MR, L NF-kapp B is required for UV-induced JNK activation via ind ' 'tion KCdelt . Mol Cell. 2006;21(4):467-80.

24. LiWJ, Oh SJ. Diabetic cystopathy is associ ed with PARP/J/NK/mitochondrial apoptotic pathway-mediated bladde poptosis. Jeurourol Urodyn. 2010;29(7):1332-7.

25. Nascimento A, Mullerpatan A, - zeve M, Karande P, Cramer S. Development of phage bior anning stra ies,to identify affinity peptide ligands for kapp ils hain Fab igrgments. Biotechnol Prog. 2019;35(6):e2884

26. Khan AP, Poisson LM- hat VB, Fer S, Zhao R, Kalyana-Sundaram S, et al. Quantitati e pro mic profikng of prostate cancer reveals a role for miR-128 in pros cr Cell Proteomics. 2010;9(2):298-312.

27. Mehrpouya-Bahra. Miranda K, Singh NP, Zumbrun EE, Nagarkatti M, Nagark ${ }^{+t i}$ PS. Role or KORNA in CB1 antagonist-mediated regulation of adipo macrophage polarization and chemotaxis during dietinduced c besity. siol Chem. 2019;294(19):7669-81.

28. Wang Q, LI XP, Zhou X, Yang CF, Zhu Z. A single-nucleotide polymorphism in Inc-LAMC $2-1: 1$ interferes with its interaction with miR-128 to alter the ression of deleted in colorectal cancer and its effect on the survival rà of subjects with ovarian cancer. J Cell Biochem. 2020. https://doi. ord /10.1002/jcb.29597.

L, Ren J, Ba L, Song C, Zhang Q, Cao Y, et al. MSTN attenuates cardiac hypertrophy through inhibition of excessive cardiac autophagy by blocking AMPK/mTOR and miR-128/PPARgamma/NF-kappaB. Mol Ther Nucleic Acids. 2019;19:507-22.

30. Madhyastha R, Madhyastha H, Nakajima Y, Omura S, Maruyama M. MicroRNA signature in diabetic wound healing: promotive role of miR-21 in fibroblast migration. Int Wound J. 2012;9(4):355-61.

31. Adlakha YK, Saini N. miR-128 exerts pro-apoptotic effect in a p53 transcription-dependent and-independent manner via PUMA-Bak axis. Cell Death Dis. 2013;4:e542.

\section{Publisher's Note}

Springer Nature remains neutral with regard to jurisdictional claims in published maps and institutional affiliations.

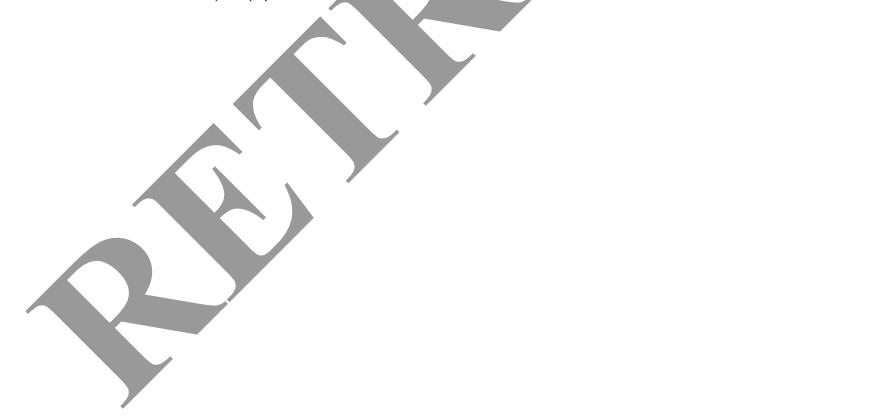

Ready to submit your research? Choose BMC and benefit from:

- fast, convenient online submission

- thorough peer review by experienced researchers in your field

- rapid publication on acceptance

- support for research data, including large and complex data types

- gold Open Access which fosters wider collaboration and increased citations

- maximum visibility for your research: over 100M website views per year

At $\mathrm{BMC}$, research is always in progress.

Learn more biomedcentral.com/submissions 